\title{
INTEGRATION OF THE ASG-EUPOS PERMANENT STATIONS WITH FIRST ORDER NATIONAL GEODETIC NETWORKS - MEASUREMENTS AND RESULTS
}

\author{
Leszek Jaworski, Anna Swiatek, Ryszard Zdunek, Janusz B. Zielinski \\ Space Research Centre Polish Academy of Sciences \\ Warsaw, Poland \\ leszek@cbk.waw.pl, ana@cbk.waw.pl,rysiek@cbk.waw.pl, jbz@cbk.waw.pl
}

\begin{abstract}
The ASG-EUPOS network - the active geodetic network was established in Poland in 2008. The 2010/2011 campaign was the second one managed to integrate the ASG-EUPOS network with the first order national geodetic networks in Poland. As the result the station coordinates were determined in the uniform coordinate frame. The paper describes the measurements carried out for data acquisition as well as the data processing method. The results present analyses of differences between selected variants of solutions and show some problems encountered during the calculation.
\end{abstract}

Keywords: GPS, GNSS, geodetic network,

\section{INTRODUCTION}

The main condition for establishing and use of new network in the national geodetic coordinate systems is to connect it with existing networks. The ASG-EUPOPS network was created in 2008. The GPS or GNSS receivers started permanent observations for nearly 100 sites. The integration process has been divided into two parts. Two campaigns were carried out: first one in 2008 and the second one in 2010/2011. The measurements in both of them were managed under the conditions that ensured the highest accuracy of the designated coordinates of new ASG-EUPOS stations.

The 2008 campaign and its results were described earlier in (Jaworski et al., 2008). This article describes mainly the 2010/2011 campaign. The 2008 campaign will also be mentioned due to the conditions required in processing the data. Before the 2010/2011 campaign was carried out, the set of eccentric points for each of main point of ASG-EUPOS network were established. Each ASG-EUPOS station has at least one eccentric point of class A. The points of class A were established similarly to POLREF main point i.e. with the main ground marker surrounded by concrete square plate. The points of class B were established similarly to direct points. The measuring campaign itself was a huge logistical undertaking. It involved 50 teams equipped with Trimble R8 GNSS receivers which measured a total of nearly 500 field points. The preliminary results of computations were presented at the EUREF symposium 2011, held in Chisinau, Moldova and published in Proceedings (Swiatek et al., 2012). 


\section{MEASUREMENTS}

The measurements taken in the 2010/2011 campaign were managed by Department of Planetary Geodesy of Space Research Centre and carried out by consortium created in the following constitution:

- OPGK Lublin Ltd. - leader

- Space Research Centre Polish Academy of Sciences

- PPGK Warsaw Ltd.

- PPG Warsaw Ltd.

- OPGK Lodz Ltd.

- PMG Katowice Ltd.

All GNSS measurements in the 2010/2011 campaign were divided into three parts:

The first one, carried from 12.10.2010 to 14.11.2010 - the autumn part. The measurements were stopped to fulfil the measurement requirements that eccentric stations could be measured only after 4 months after the date of their stabilisation.

The second one, carried from 07.12.2010 to 12.12 .2010 - the winter part. The measurements were stopped because of the weather conditions - severe frost, heavy snowfalls.

The third one, carried from 23.03.2011 to 04.04.2011 - the spring part. The measurements were carried out to completion.

During the 2010/2011 campaign the field points of: Polish GPS and classical networks were measured together with ASG-EUPOS stations, their eccentricities and selected EUPOS stations from neighbourhood counties (Germany, Czech Republic, Slovakia, Lithuania). To connect this sub-network to ITRF the data from 15 IGS and/or EPN stations were used. In total 626 points were measured including:

- 142 permanent stations of Polish EPN/IGS, ASG-EUPOS, SAPOS, LITPOS, SKPOS and CZEPOS stations,

- 242 POLREF points,

- 4 Polish EUVN points,

- 31 first order classical network points,

- 16 direction points,

- 114 eccentric station class A for ASG-EUPOS stations,

- 77 eccentric station class B for ASG-EUPOS stations.

Because of different types of measured points the different time of observation for them was planned:

- permanent 24-hour observations (start 0:00 UT stop 24:00 UT) - for permanent stations of Polish EPN/IGS, ASG-EUPOS, SAPOS, LITPOS, SKPOS and CZEPOS,

- two 24-hour observation sessions (start 12:00 UT stop 12:00 UT next day) with minimum break of 24 hours between sessions - for main field points (POLREF, EUVN, first order classical network) and eccentric stations class A,

- two 2-hour observation sessions with minimum break of 1 hour between sessions - for direction points and eccentric stations class B.

To ensure high accuracy of the appointed point coordinates the special conditions had to be fulfilled:

- all measurements were made using homogeneous equipment - Trimble R8 GNSS receivers,

- measurements for 24-hour sessions had to be continuous (the breaks longer than 60 minutes induced re-measurement),

- observation interval for measurements -5 seconds,

- elevation cut off for observed satellites - 0 degree,

- accuracy of antenna height measurements - not bigger than $0.005 \mathrm{~m}$,

- centering of antenna above the marker - not bigger than $0.003 \mathrm{~m}$.

\section{DATA PROCESSING}

All computations were carried out in Bernese GPS Software ver. 5.0 in newest release (11-May-2011) containing all bug fixes and improvements of the previous releases. 
According to the contract conditions, observation data from all 538 points were used for computations. The data processing for main points was prepared in three variants:

- all GPS observations from 24-hour sessions for elevation cut off 5 and 10 degrees,

- all GPS and GLONASS from 24-hour sessions.

The computations were carried out according to the procedure recommended in guidelines $(\mathrm{C}$. Bruyninx et. al (2010)) with the following parameters:

- minimally constrained solution for baselines network,

- L3 - ionosphere free linear combination for phase observation computations,

- introducing the fixed L1 and L2 ambiguities resolved from QIF strategy for baseline - for GPS observable (GLONASS observable were resolved as a float),

- combined IGS final orbit together with IGS Earth Rotation Parameters,

- Sun and Moon ephemeris model - standard DE405,

- zenith tropospheric correction estimated for every hour with „dry Neill” mapping function and taking NMF for each point with horizontal gradient computed with TILTING option,

- weighting observation as a function of satellite zenith angle ( $\cos z)$,

- Precession and Nutation parameters - standard IAU2000,

- Tidal model - standard IERS2000,

- loading ocean effect - model FES2004,

For data processing the absolute phase centre models IGS_05.ATX and for individual models EPN_05.ATX were used together with individual models for selected antennas delivered by the Head Office of Geodesy and Cartography.

Because all station coordinates were to be estimated in ITRF2005, for the reference stations coordinates for realisation EPN_A_ITRF2005_C1600 (dates 23/10/2010) were taken and rotated to observation epoch.

The network design and different equipment working on permanent stations caused the strategy for baseline definition. The baselines form a stars-like structure with the main nodes connected to the foreign EPN stations (see Figure 1). As the main nodes for baseline construction the permanent stations were selected. They were:

- Polish EPN/IGS permanent stations: BOR1 12205M002, BOGI 12207M003, LAMA 12209M001, KRAW 12218M001 (and KRA1 12218M002) and WROC 12217M001

- ASG-EUPOS stations working in EPN as well and equipped with GNSS Trimble NETR5 receivers: BPDL 12223M001, BYDG 12224M001, GWWL 12225M001, LODZ 12226M001, REDZ 12227M001, SWKI 12228M001 and USDL 12229M001.

The definition of the baseline network is presented in Figure 2.

\section{RESULTS}

Various parts of the campaign were carried out in different seasons (autumn, winter and spring), which potentially introduced additional noise to the solution, associated with the measurement conditions and other effects of a seasonal nature.

In order to check the stability and cross-compliance of solutions the selected parts of measurement campaign were calculated as separate sets of data. The comparison showed an increase of errors the repeatability determining the coordinates in the second part of the campaign (winter) by about $30 \%$ for all components of the points' positions (see Figure 3 ). 


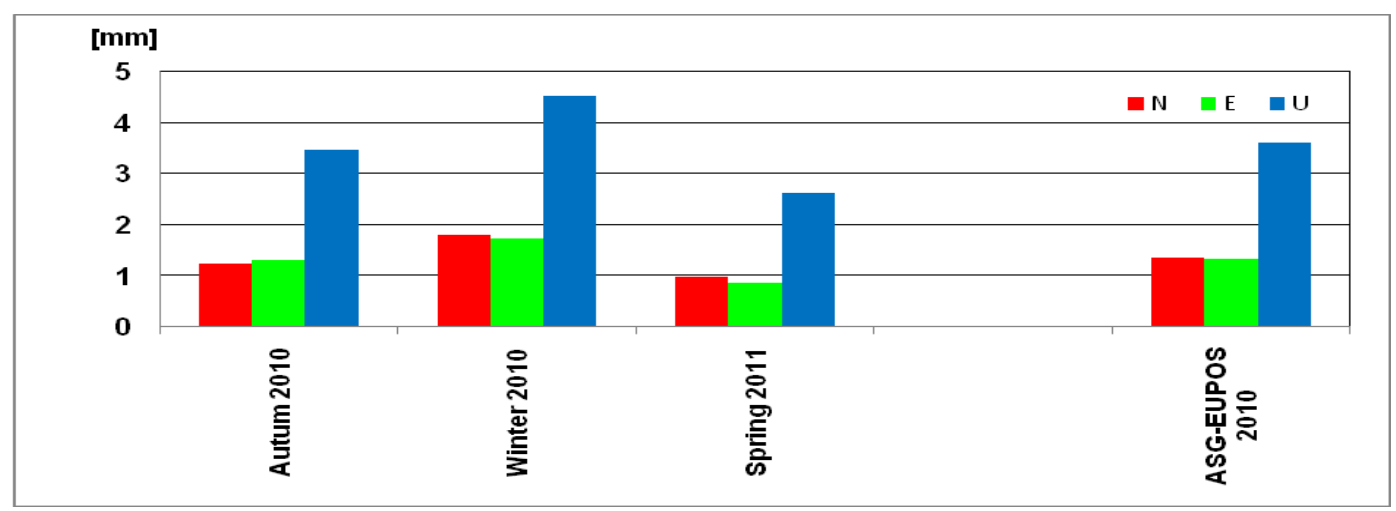

Figure 3. Daily repeatability in north, east and up components for particular parts and whole campaign for elevation cut off angle for satellites - 5 degrees.

Because different parts of the campaign included a different number of sessions and measured field points, which could distort the result of the comparison, a similar analysis was made with respect only to the permanent stations. The results confirmed the conclusions obtained for all points (see Figure 4.).

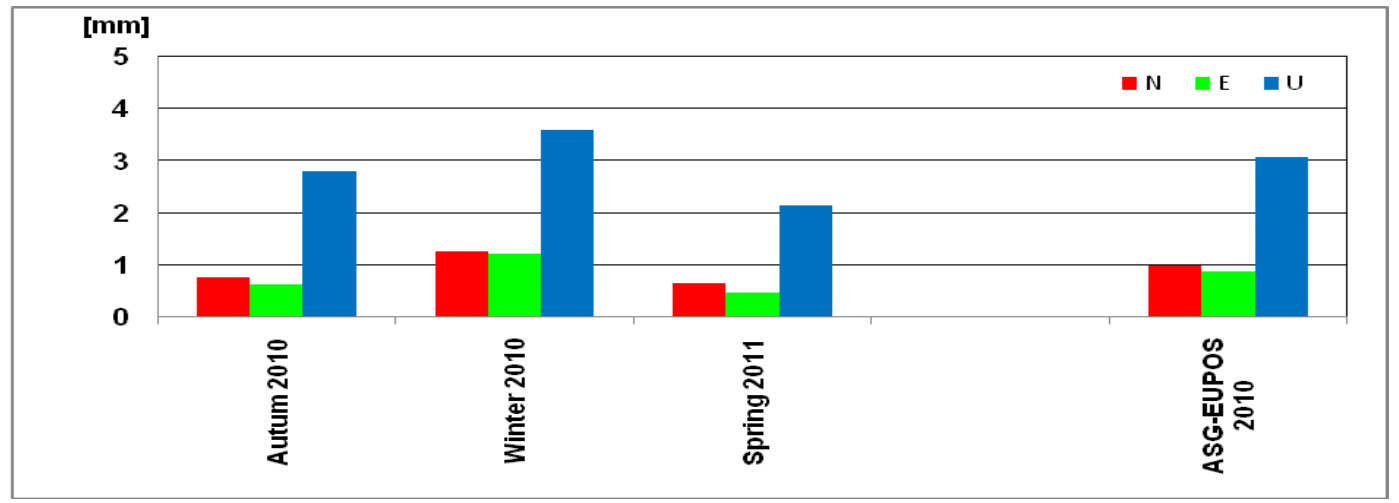

Figure 4. Daily repeatability in north, east and up components for permanent stations for particular parts as well as for whole campaign for elevation cut off angle for satellites - 5 degrees.

Comparing the results for solutions with a mask of 5 and 10 degrees, it appeared that the smaller errors occur for the elevation cut off 5 degrees. This was true in particular for the field points of weakest solutions. The results of a comparison of the points coordinates in the horizontal and vertical components, obtained for independent measurement sessions, for both variants are presented in Figures 5 and 6.

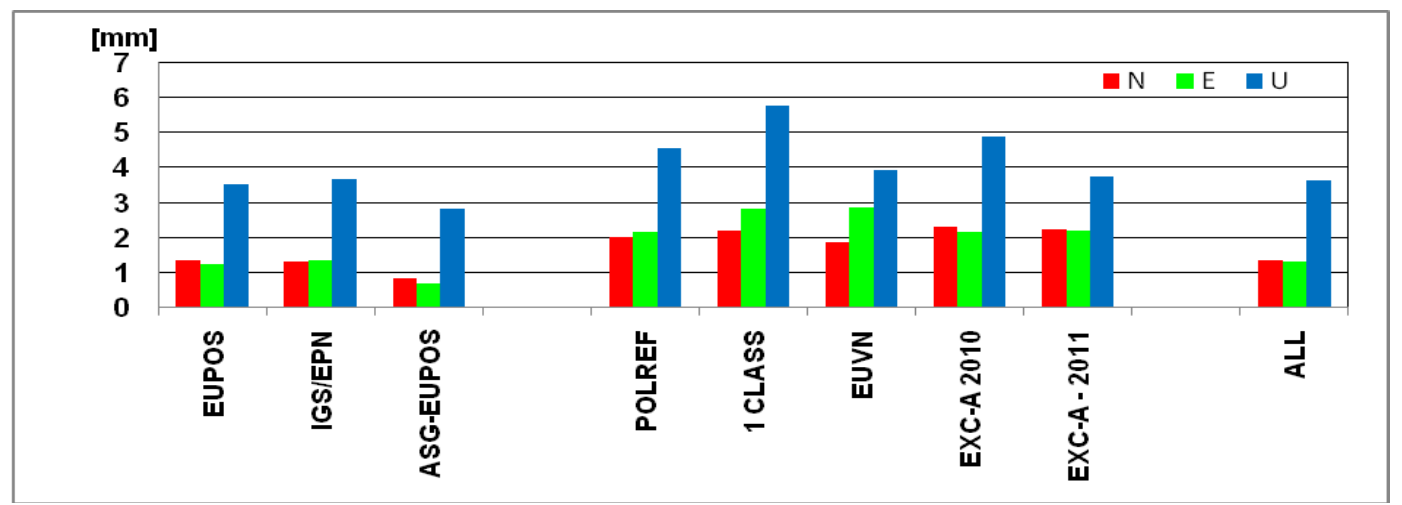

Figure 5. Daily repeatability in north, east and up components for different types of measured points for elevation cut off angle for satellites - 5 degrees. 


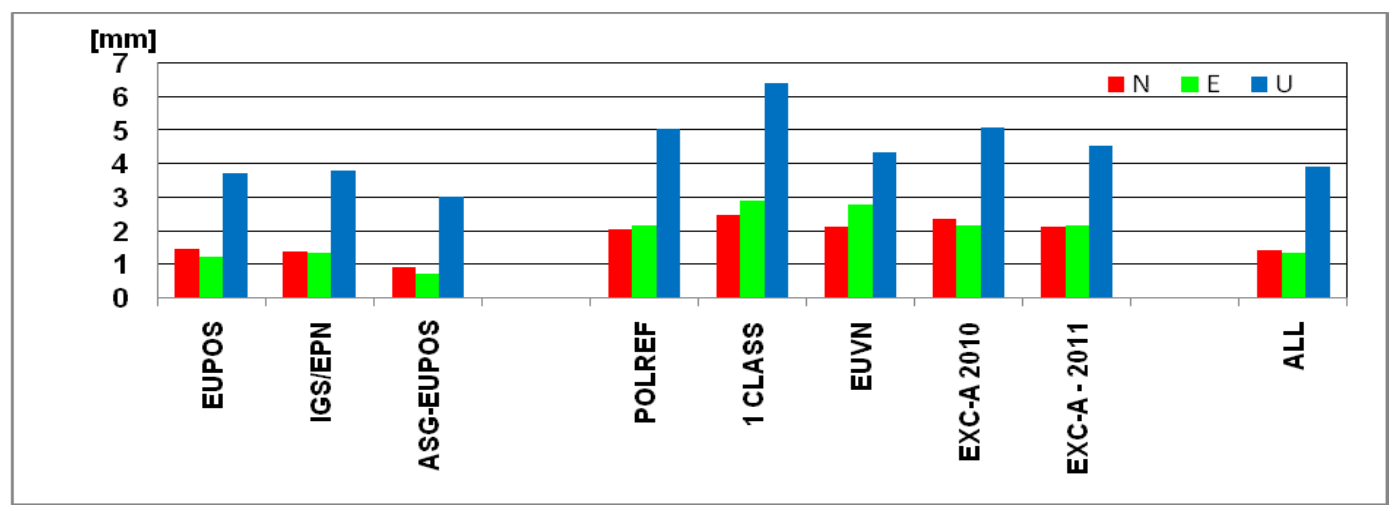

Figure 6. Daily repeatability in north, east and up components for different types of measured points for elevation cut off angle for satellites - 10 degrees.

The increase in errors for the vertical component of field points is especially clear. For the permanent stations the effect of an increase of accuracy is smaller. This is probably due to measurement conditions on individual points. Field points have in many cases the obscured horizon, therefore the reduction of mask in processing increases the number of observations and improves the stability of the solution. Permanent stations due to the locations on the roofs of the buildings have a much better observation and increasing the number of observations has less impact on the results of the solution.

For the processing with the mask of 5 degrees in the various sessions $70-80 \%$ of ambiguities were resolved, while for the mask of 10 degrees $85-90 \%$. Significant higher errors observed for the points IClass are also caused by taking into account the analysis points, which due to the obscured horizon are completely unsuitable for precise GPS measurements.

One of the main points of the contract with the Head Office of Geodesy and Cartography was to make the joint solution for data from 2008 and 2010/2011 campaigns.

The original solution of the 2008 campaign was prepared according to other assumptions than those adopted for the campaign of 2010 (Jaworski et al., 2008). Therefore, it was decided to perform a recomputing data from the 2008 campaign, according to the parameters adopted in the current contract and absolute antennas phase models used for 2010/2011 campaign. The baseline definition for 2008 campaign remained unchanged.

For 2008 campaign the differences between processing for the mask 5 and 10 degrees are smaller than for 2010/2011 campaign (see Figures 7 and 8).

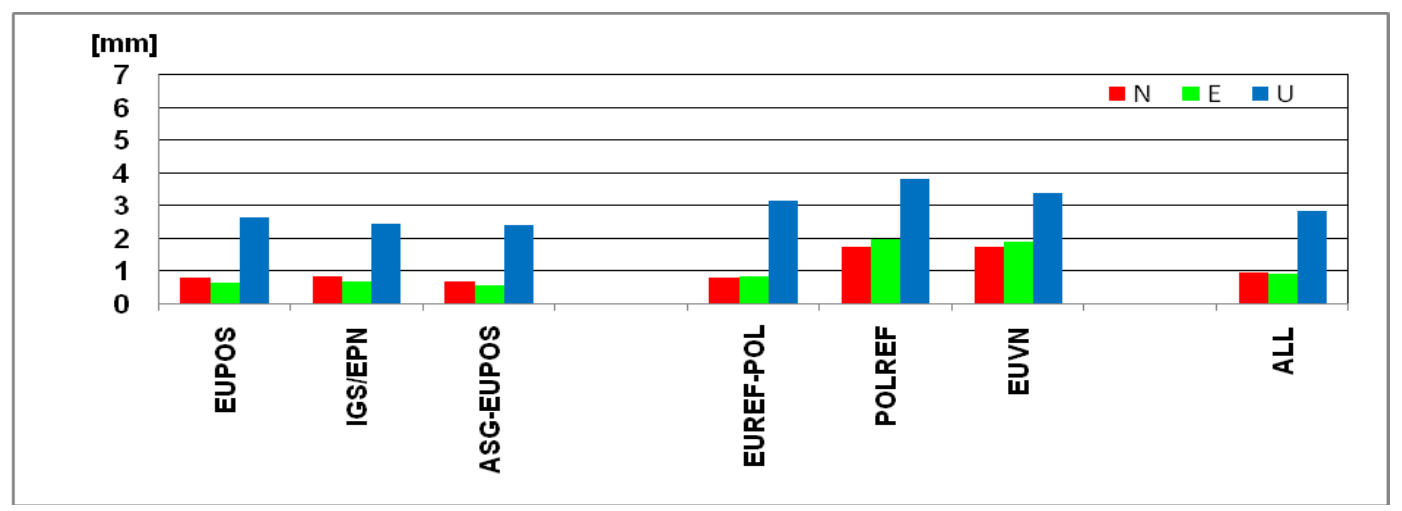

Figure 7. Daily repeatability in north, east and up components for different types of points measured in 2008 campaign for elevation cut off angle for satellites - 5 degrees. 


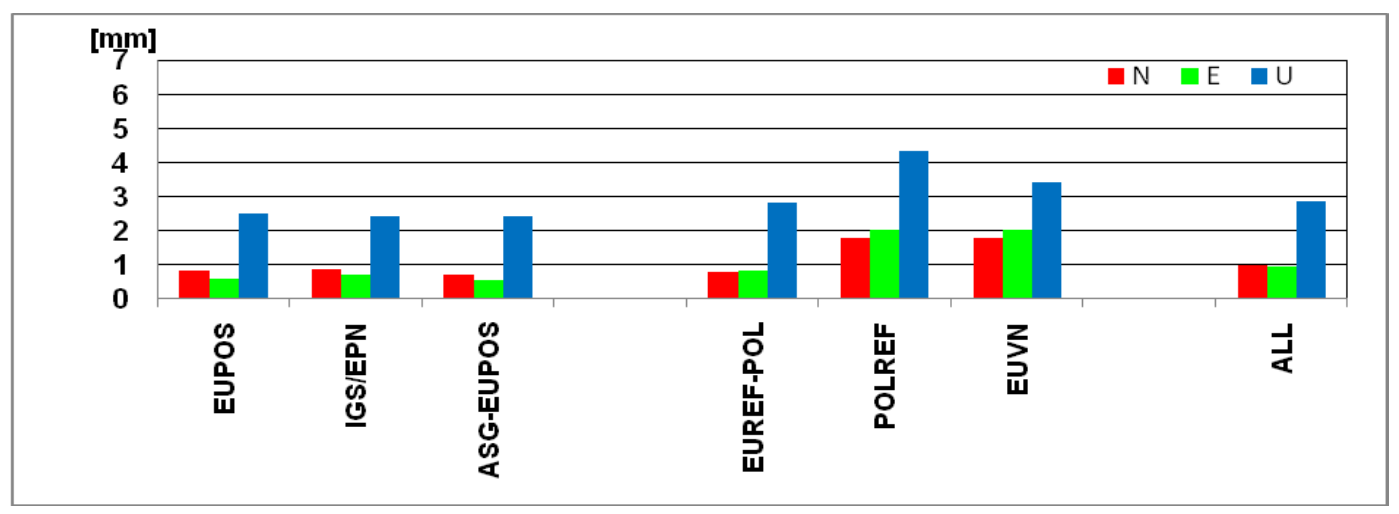

Figure 8. Daily repeatability in north, east and up components for different types of points measured in 2008 campaign for elevation cut off angle for satellites - 10 degrees.

The comparison of solutions (new and previous) prepared for 2008 campaign for mask of 10 degrees consistency. Mean differences in the horizontal components are less than $1 \mathrm{~mm}$, while for height is $2.0 \mathrm{~mm}$.

For joint solution, prepared for both campaigns there were 692 points calculated. The common calculation epoch for coordinates was 2011.0. Mean errors for the daily repeatability for the NEU components were respectively:

$$
\mathrm{N} \pm 1.39 \mathrm{~mm}, \mathrm{E} \pm 1.31 \mathrm{~mm}, \mathrm{U} \pm 3.43 \mathrm{~mm}
$$

For the solution with GPS and GLONASS data computation some observation sessions for selected stations or points were rejected by the program. It happened because of poor data for GLONASS observations. Mean errors for the daily repeatability for the NEU components were very similar to GPS only solution and amounted respectively:

$$
\mathrm{N} \pm 1.31 \mathrm{~mm}, \mathrm{E} \pm 1.61 \mathrm{~mm}, \mathrm{U} \pm 3.41 \mathrm{~mm}
$$

Comparison of GPS only computations with GPS plus GLONASS showed consistency. Mean differences for the horizontal component amounted to $\pm 0.8 \mathrm{~mm}$, while for the height $\pm 1.9 \mathrm{~mm}$.

While analysing the differences depending on the type of points the smallest discrepancies occurred for the permanent stations, both equipped with GPS receivers and GPS and GLONASS. Much larger discrepancies could be observed at field points, especially in cases of the obstructed horizon on the point. This suggests that improved solutions for the computation of GPS and GLONASS data were inconsistent. In some cases the significant degradation of results in relation to the development of GPS can be observed because of weak GLONASS data. It can be concluded that in some cases the stability of the registration data for the GLONASS system is lower than for the GPS system for the Trimble R8 GNSS receivers. The points with the largest differences between the GPS and GPS plus GLONASS solutions are presented in table 1.

Table 1. The point of the largest coordinate differences between GPS and GPS plus GLONASS solutions.

| NUM |
NAME

During the 2010/2011 campaign the Head Office of Geodesy and Cartography managed the change of measurement equipment for selected stations. It caused changes in coordinate of those stations. 
The analyses prepared for those cases showed that only for antennas with individual phase centre variation models observed changes are negligible. The example of that case is KATO station. Replacing the Trimble NETRS receiver with ZEPHYR GEODETIC antenna to Trimble NETR5 receiver with ZEPHYR GEODETIC 2 antenna caused changes in NEU components of:

$$
\mathrm{N}-0.5 \mathrm{~mm}, \mathrm{E}-0.1 \mathrm{~mm}, \mathrm{U}+1.4 \mathrm{~mm}
$$

Daily repeatability of coordinates for that station is shown in Figure 9.

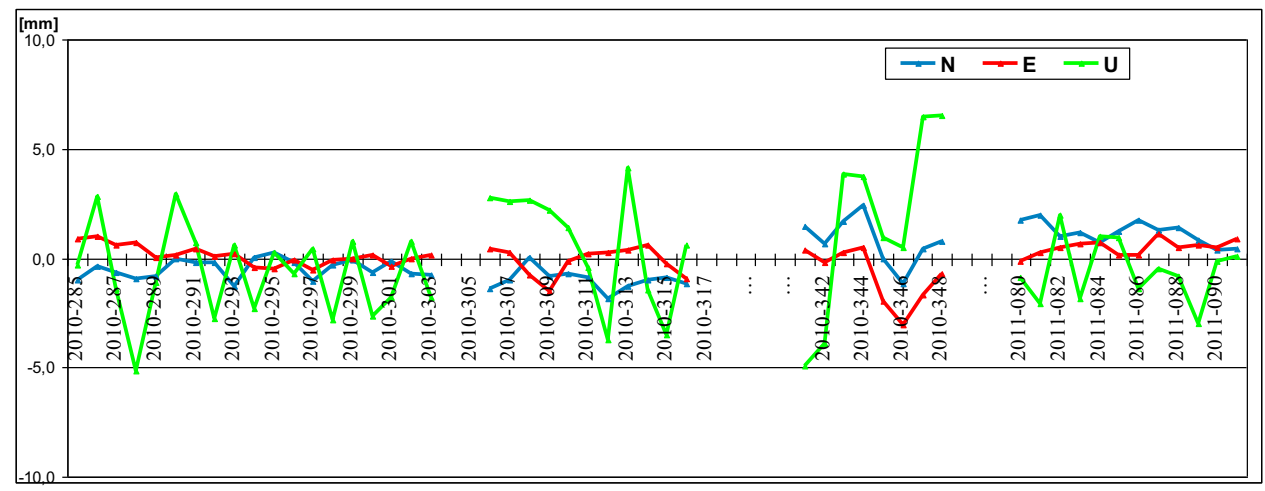

Figure 9. Daily repeatability in north, east and up components for station KATO measured during the 2010/2011 campaign.

In cases when even one of the antennas has not appointed the individual phase centre variation model, changes in coordinates are visibly bigger and cannot be considered as negligible. These were the cases of stations MIMA and SOCH when the Trimble NETRS receivers with ZEPHYR GEODETIC antennas were replacing with Trimble NETR5 receivers with ZEPHYR GEODETIC 2 antennas. In these cases the ZEPHYR GEODETIC, antennas didn't have individual models. Daily repeatability of coordinates for these stations is shown respectively in Figures 10 and 11.

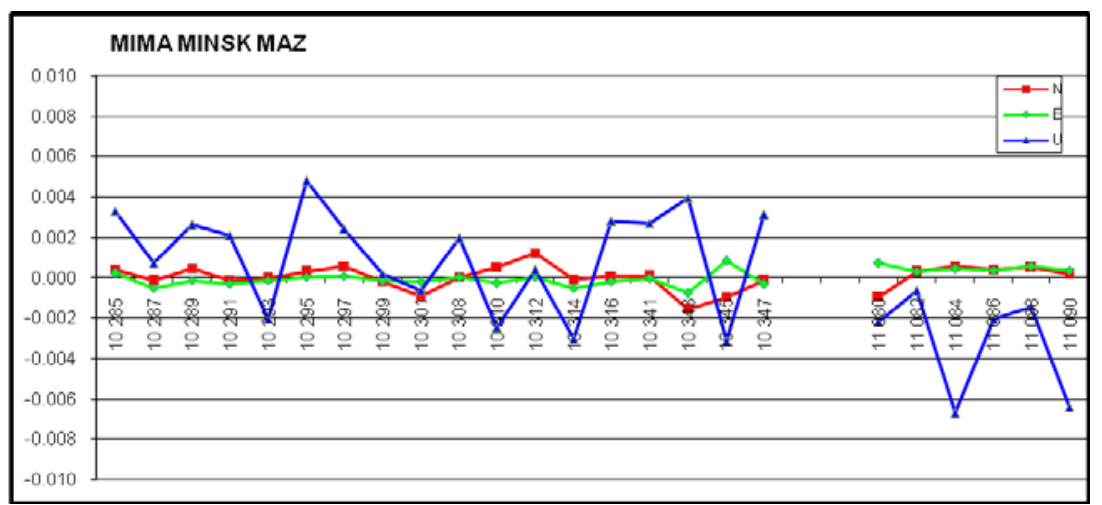

Figure 10. Daily repeatability in north, east and up components for station MIMA measured during the 2010/2011 campaign. 


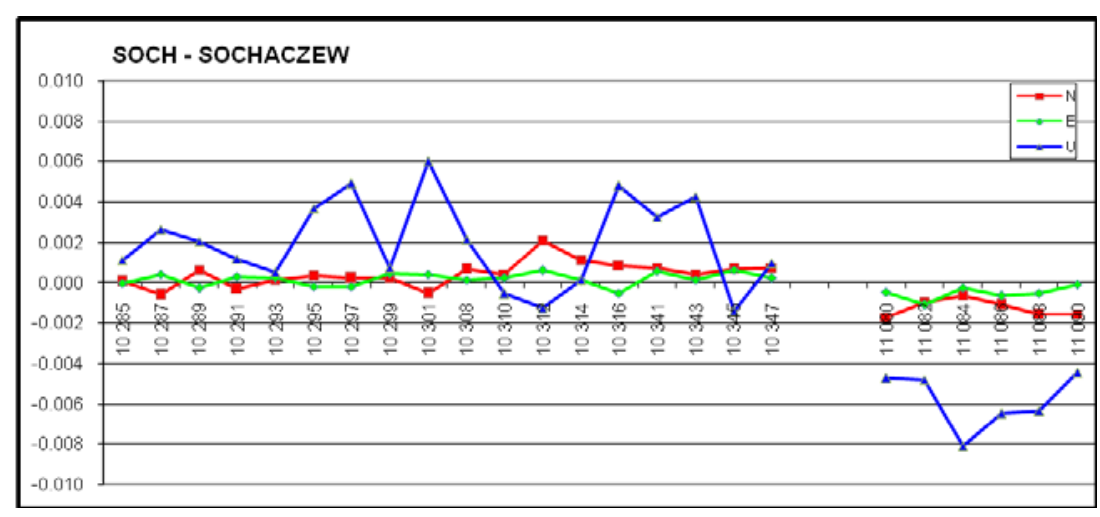

Figure 11. Daily repeatability in north, east and up components for station SOCH measured during the 2010/2011 campaign.

For MIMA stations changes in coordinates were, respectively:

$$
\mathrm{N}+0.2 \mathrm{~mm}, \mathrm{E}-0.4 \mathrm{~mm}, \mathrm{U}+4.1 \mathrm{~mm},
$$

when for SOCH stations they were, respectively:

$$
\mathrm{N}+2.0 \mathrm{~mm}, \mathrm{E}-1.1 \mathrm{~mm}, \mathrm{U}+7.8 \mathrm{~mm} \text {. }
$$

It can clearly be seen that the main changes occur in vertical components for both stations.

Exceptionally big changes in station coordinates were observed for station WODZ. In that case, the receiver ASHTECH UZ-12 with DORNE MARGOLIN ASHTECH antenna was replaced with Trimble NETR5 with ZEPHYR GEODETIC 2 antenna. Daily repeatability of coordinates for that station shows changes not only in vertical component but even in horizontal (see Figure 12). The main changes for NEU components were, respectively:

$$
\mathrm{N}+3.4 \mathrm{~mm}, \mathrm{E}-5.3 \mathrm{~mm}, \mathrm{U}+9.8 \mathrm{~mm}
$$

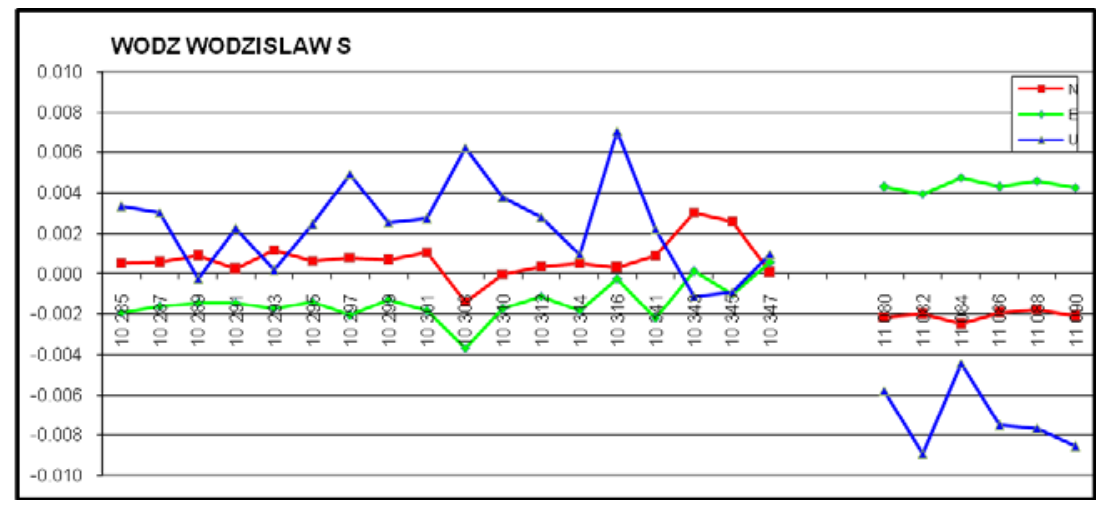

Figure 12. Daily repeatability in north, east and up components for station WODZ measured during the 2010/2011 campaign.

\section{CONCLUSIONS}

In both campaigns (2008 and 2010/2011) all field points were measured with homogenous equipment. Different types of receivers and antennas occurred only on a number of permanent stations.

This allowed to determine the station coordinates with high accuracy. The comparison of the field points coordinates obtained in processing showed high compliance with previous campaigns: $\pm 0.01 \mathrm{~m}$ in horizontal components and not bigger than $\pm 0.014 \mathrm{~m}$ for vertical components. For the permanent stations some results in vertical component achieved $-0.030 \mathrm{~m}$, but it was caused by absence of individual antennas phase centre variation models.

Assuming that earlier campaigns were carried out in years: 1992, 1994/1995, 1997 and 2001 the reference epochs for coordinates are very distant in time. Such a distant epochs allow us to analyse point position 
changes in time. The analysis of coordinates comparison of the previous results with the recent ones will be presented in future works.

\section{REFERENCES}

Bruyninx C., Z. Altamimi, A. Caporali, A. Kenyeres, M. Lidberg, G. Stangl, and J.A. Torres (2010). Guidelines for EUREF Densifications,

Jaworski L., A. Swiatek, R. Zdunek, J.B. Zielinski (2008). Data processing of the ASG-EUPOS network test campaign, Reports on Geodesy, No 2(85), pp. 113-124.

Swiatek A., L. Jaworski, R. Zdunek, J. B. Zielinski (in press) Preliminary results of the GNSS Campaign for integration of the ASG-EUPOS permanent stations with first order national geodetic networks, EUREF 2011 Proceedings.

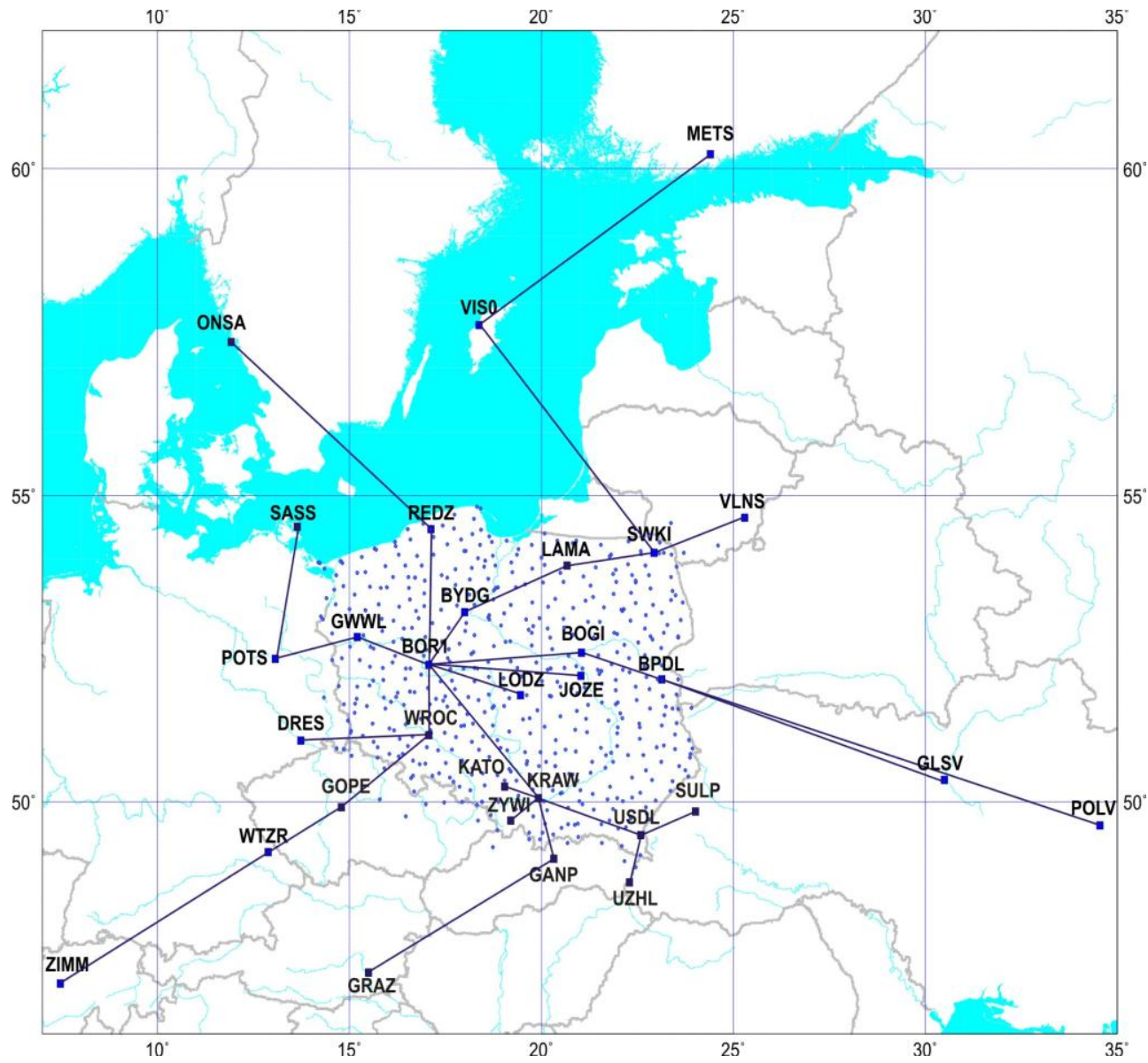

Figure 1. The scheme of connection vectors to foreign IGS/EPN permanent stations for 2010/2011 campaign 


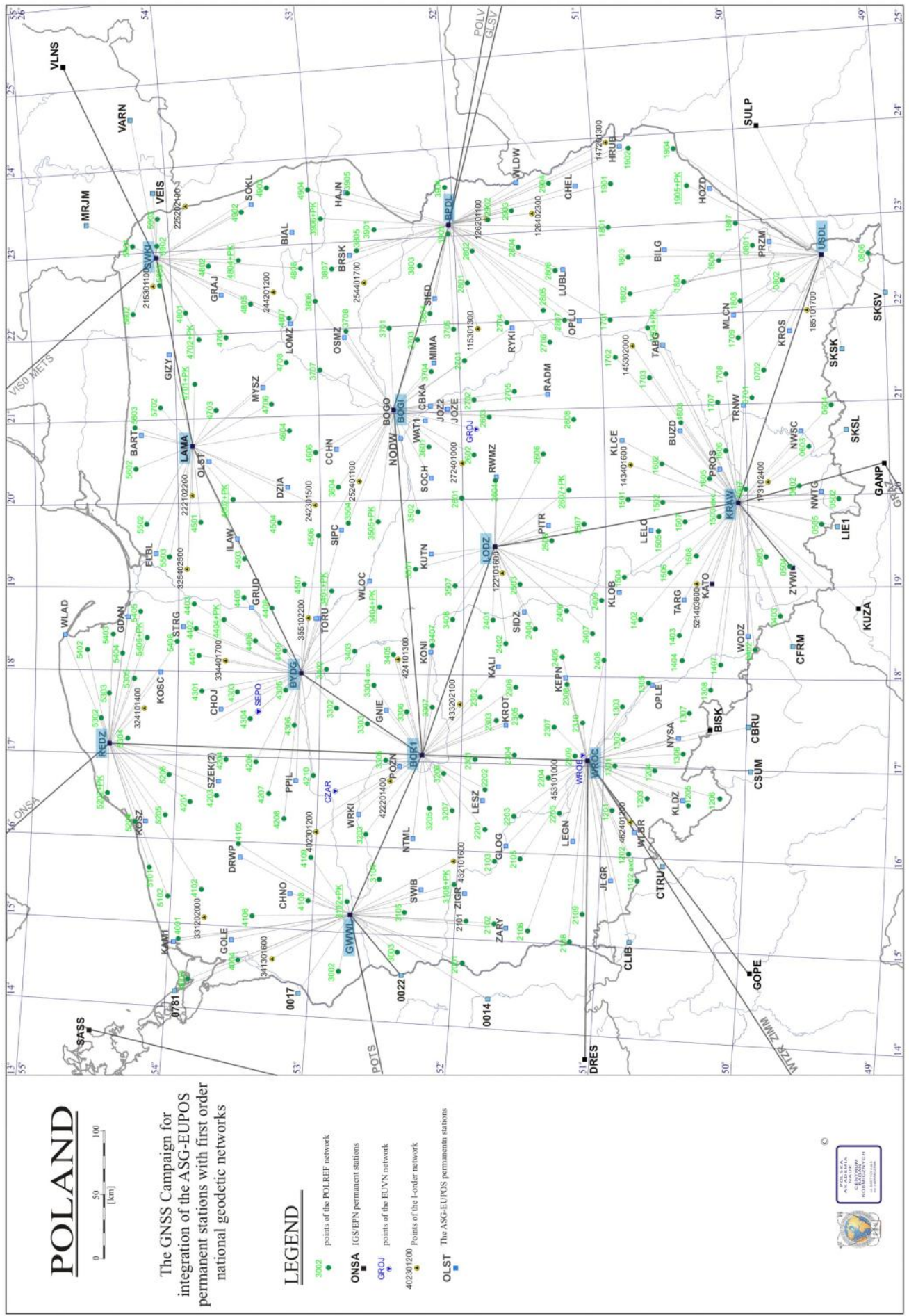

Figure 2. Baseline definition for processing of 2010/2011 campaign 